\title{
Proposta de UEPS para o estudo da Hidrostática no ensino médio, orientada por um kit didático: braço hidráulico e escavadeira hidráulica
}

\author{
Alcilene Balica Monteiro ${ }^{1}$, José Carlos da Silva Oliveira ${ }^{2}$, Wendel Ricardo de Souza Rego ${ }^{3}$, \\ Bruno Ferreira de Araujo ${ }^{4}$, Cesar Junior Rodrigues Perez ${ }^{5}$, Edivane de Lima Bezerra ${ }^{6}$ \\ 1, 2, 3 Universidade Federal do Acre (UFAC) \\ 4, 5, 6 Instituto Federal do Acre (IFAC)
}

Palavras-Chave: Braço Hidráulico, Escavadeira Hidráulica, UEPS.

\section{Introdução}

Propostas por Moreira (2011), as Unidades de Ensino Potencialmente Significativas (UEPS), vem sendo inseridas nas salas de aula, como mais uma alternativa didática para os professores inovarem no ensino, seja na educação básica ou superior, de modo que o objetivo seja a aprendizagem. Segundo o autor, as UEPS são construídas de forma sistemática, organizada e com sequencias de aulas baseadas na Teoria da Aprendizagem Significativa (TAS), visando facilitar o processo de construção do conhecimento.

De acordo com Ausubel (1968), a Aprendizagem Significativa é o processo em que novas informações são incorporadas e reorganizadas na estrutura cognitiva do estudante, permitindo-os utilizarem conhecimentos adquiridos no cotidiano, partindo da análise dos dados disponibilizados na aprendizagem primária e, transformando a apreciação e a absorção destas informações em conhecimento útil. Nesse processo, faz-se necessário que o professor passe por mudanças didáticas e metodológicas de ensino.

Estudos utilizando kits didáticos, em turmas de Ensino Médio, foram realizadas por vários autores, a exemplo de Barbosa et al. (2017), ao demonstrar o ensino da Mecânica dos fluidos, através de artefatos tecnológicos - uma escavadeira hidráulica, um guindaste hidráulico, uma mão mecânica e uma aranha hidráulica, confeccionados apenas com sucatas e materiais de baixo custo. Frassi et al. (2017) apresentam os conceitos teóricos acerca de Hidrostática e Hidrodinâmica em uma aula de Física, utilizando o parafuso de Arquimedes como foco da aula, elucidando os principais conceitos e aplicando-os praticamente na confecção de um protótipo de baixo custo da referida máquina. A intervenção realizada por Frassi et al. (2017) deu-se em uma turma de nível médio do IFES - Cariacica, Espirito Santo.

Esses estudos revelam a eficácia da utilização de materiais lúdicos em aulas de Física, quando o tema em estudo é a Hidrostática e faz reflexão sobre as UEPS, as quais, segundo os autores, permitem aulas diferenciadas e incentivam o ensino da Física, pois evidenciam uma evolução conceitual por parte dos estudantes e podem potencializar as habilidades dos mesmos.

Nesse contexto da teoria de Aprendizagem Significativa, o presente trabalho tem o objetivo apresentar uma UEPS, como metodologia didática para o ensino e aprendizagem dos temas da Hidrostática no ensino médio, orientada por um kit didático: braço hidráulico e escavadeira hidráulica.

\section{Metodologia e Material}

A construção desta proposta teve o enfoque qualitativo e descritivo, por tratar-se de um método didático com o uso de kit didático, para o ensino da Hidrostática. $\mathrm{O}$ método didático apresenta uma teoria específica aliada a proposta: UEPS. Foi elaborada e aplicada uma proposta de UEPS, com adaptações, em duas turmas de $2^{\circ}$ ano do Ensino Médio do curso Técnico em Informática integrado ao ensino médio do IFAC/Campus Sena Madureira.

A UEPS proposta teve um total de 5 aulas de 50 minutos cada uma. Inicialmente foram apresentados os objetivos e a temática das aulas. Em seguida, apresentação dos conteúdos de ensino, buscando sempre os conhecimentos prévios dos estudantes, através de situações problema e exibição de vídeo de curta duração. Fixação dos conteúdos, com a manipulação do kit didático, e aplicação de quatro questões relacionadas à Hidrostática, contendo perguntas abertas e fechadas, que serviram de análise dos conhecimentos adquiridos pelos estudantes. Para finalizar, foi realizada a correção e discussão, com o cuidado de associar os conhecimentos prévios dos estudantes com

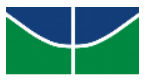


os novos adquiridos. Na Figura 1 é ilustrada uma das etapas da UEPS: manipulação do kit didático pelos estudantes.

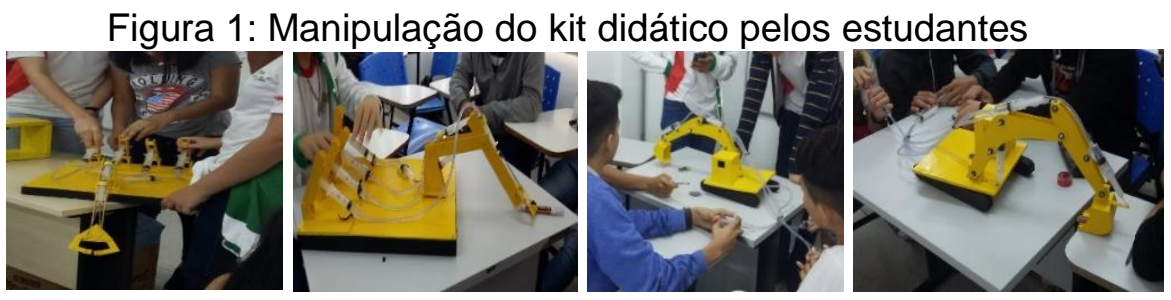

Fonte: os autores

\section{Resultados e Discussão}

Os resultados da aplicação dos questionários indicaram que a maioria dos estudantes ampliou a média de acertos nas questões, passando de um percentual de $8,3 \%$ no pré-teste para 17,4\% no pós-teste.

A partir da análise dos dados, observou-se que as atividades aplicadas no estudo, foram capazes de tornar os temas de Física e da Hidrostática mais interessantes, principalmente aquelas que envolveram situações do dia a dia associadas ao kit didático, vindo a contribuir ainda, no esclarecimento dos conceitos abordados. Soma-se a isto, o fato da proposta alcançar bons resultados de aprendizagem, obtidos principalmente em torno das perguntas sobre temas gerais de Física, bem como os conceitos de massa especifica, peso especifico, pressão atmosférica, prensa hidráulica, empuxo, entre outros. Também houve aumento na compreensão sobre o funcionamento da escavadeira e os aspectos relacionados à sua utilização no dia a dia da construção civil.

\section{Conclusões}

Esta metodologia possibilitou aos estudantes perceberem diversas aplicações da Hidrostática e sua importância na vida moderna, com os avanços tecnológicos e vivenciando aulas que envolveram a utilização de kit experimental. Os dados apresentados representam um dos resultados parciais de um trabalho maior relacionado à temática de UEPS e o ensino da Hidrostática.

\section{Agradecimentos}

Ao IFAC/Campus Sena Madureira, por permitir a aplicação da proposta e à Capes pela concessão da bolsa de estudos.

\section{Referências}

AUSUBEL, D. P. Educational psychology: a cognitive view. Nova York: Holt, Rinehart and Winston, INC., 1968.

BARBOSA, D. M. et al. Ensinando mecânica dos fluidos no ensino básico através de protótipos de brinquedos hidráulicos. Artigo Científico. XXII Simpósio Nacional de Ensino de Física - SNEF, São Carlos, SP - Brasil - 23 a 27 de jan 2017.

FRASSI, L. et al. O parafuso de Arquimedes: um laboratório teórico e prático de hidrostática e hidrodinâmica. Artigo Científico. XXII Simpósio Nacional de Ensino de Física - SNEF, São Carlos, SP - Brasil - 23 a 27 de jan 2017. MOREIRA, M. A. Unidades de Ensino Potencialmente Significativas - UEPS. Aprendizagem Significativa em Revista, v. 1, n. 2, 2011. 